\title{
Does cognitive behavioral therapy alter mental defeat and cognitive flexibility in patients with panic disorder?
}

\author{
Shinobu Nagata ${ }^{*}$, Yoichi Seki², Takayuki Shibuya' ${ }^{2}$ Mizue Yokoo' ${ }^{1}$ Tomokazu Murata' ${ }^{1}$, Yoichi Hiramatsu', \\ Fuminori Yamada ${ }^{1}$, Hanae Ibuki ${ }^{1}$, Noriko Minamitani ${ }^{1}$, Naoki Yoshinaga ${ }^{1,3}$, Muga Kusunoki ${ }^{4}$, Yasushi Inada ${ }^{4}$, \\ Nobuko Kawasoe ${ }^{5}$, Soichiro Adachi ${ }^{5}$, Keiko Oshiro ${ }^{6}$, Daisuke Matsuzawa' ${ }^{1}$, Yoshiyuki Hirano ${ }^{6}$, \\ Kensuke Yoshimura ${ }^{7}$, Michiko Nakazato ${ }^{7,8}$, Masaomi lyo ${ }^{7}$, Akiko Nakagawa ${ }^{8}$ and Eiji Shimizu ${ }^{1,8}$
}

\begin{abstract}
Objective: Mental defeat and cognitive flexibility have been studied as explanatory factors for depression and posttraumatic stress disorder. This study examined mental defeat and cognitive flexibility scores in patients with panic disorder (PD) before and after cognitive behavioral therapy (CBT), and compared them to those of a gender- and age-matched healthy control group.

Results: Patients with PD $(n=15)$ received 16 weekly individual CBT sessions, and the control group $(n=35)$ received no treatment. Patients completed the Mental Defeat Scale and the Cognitive Flexibility Scale before the intervention, following eight CBT sessions, and following 16 CBT sessions, while the control group did so only prior to receiving CBT (baseline). The patients' pre-CBT Mental Defeat and Cognitive Flexibility Scale scores were significantly higher on the Mental Defeat Scale and lower on the Cognitive Flexibility Scale than those of the control group participants were. In addition, the average Mental Defeat Scale scores of the patients decreased significantly, from 22.2 to 12.4, while their average Cognitive Flexibility Scale scores increased significantly, from 42.8 to 49.5 . These results suggest that CBT can reduce mental defeat and increase cognitive flexibility in patients with PD

Trial registration The study was registered retrospectively in the national UMIN Clinical Trials Registry on June 10, 2016 (registration ID: UMIN000022693).
\end{abstract}

Keywords: Cognitive behavioral therapy, Panic disorder, Mental defeat, Cognitive flexibility

\section{Introduction}

Panic disorder (PD) is a mental illness characterized by repeated panic attacks that exert a significant impact on daily functioning [1]. When PD symptoms intensify, anticipatory anxiety increases, making it difficult for individuals with the disorder to venture outside their homes. PD is estimated to be the 27th leading cause of nonfatal population burden [2]; the Japanese lifetime prevalence rate is $.8 \%[3]$. The Japanese comorbidity rate for PD

\footnotetext{
*Correspondence: nagata@medicalheart-shizu.jp

${ }^{1}$ Department of Cognitive Behavioral Physiology, Graduate School of Medicine, Chiba University, Chiba, 1-8-1 Inohana, Chuo-ku, Chiba-shi, Chiba 260-8670, Japan

Full list of author information is available at the end of the article
}

and depression is approximately $50-60 \%$ [4]. Failure to seek PD treatment and the exacerbation of concomitant symptoms increase the likelihood of comorbidity with depression. The global prevalence rate for untreated PD has been estimated at 55.9\% [5], highlighting the importance of implementing PD treatment strategies.

Cognitive behavioral therapy (CBT), both in isolation and in combination with pharmacotherapy, is one of the most effective PD treatment approaches [6]. Specifically, CBT's effectiveness in treating PD has been shown to exceed both the placebo effect [7] and that of pharmacotherapy [8-10]. Although the concurrent use of CBT and medication is more effective than the use of either 
treatment separately during the acute phase, this difference in effectiveness declines over time [11-13].

Mental defeat is a thought process involving a loss of emotional autonomy and a sense of feeling broken or less than human, expressed through statements such as, "I feel like a loser." It has been shown to contribute to posttraumatic stress disorder (PTSD) [14-17]. Responsiveness to CBT is lower in patients with chronic PTSD who have experienced mental defeat [14]. Moreover, chronic pain research has shown that the severity of mental defeat is associated with the secondary occurrence of psychosocial problems, including depression and anxiety $[16,17]$.

Cognitive flexibility is defined as the mental ability to switch between two different modes of thinking; it includes the ability to adapt one's thoughts and actions in response to different situations [18]. Previous research has demonstrated that patients with anorexia nervosa [19] and PTSD [20] have less cognitive flexibility than healthy individuals. Research involving nonclinical samples has shown that cognitive flexibility is negatively associated with depression and anxiety [21]. Therefore, levels of cognitive flexibility may influence the severity of mental disorders.

To our knowledge, no previous studies have examined the effects of CBT on both mental defeat and cognitive flexibility in patients with PD. Therefore, the current study compared the effects of CBT on mental defeat and cognitive flexibility in patients with PD and healthy ageand gender-matched controls.

\section{Main text \\ Methods \\ Participants and design}

Participants were recruited through clinical referrals and web-based advertisements between April 2014 and March 2015. Fifteen patients with PD (13 women) participated in a single-arm, uncontrolled CBT trial registered in the National UMIN Clinical Trials Registry (ID: UMIN000022693) [22]. Participants met the criteria for PD according to the Diagnostic and Statistical Manual of Mental Disorders Fifth Edition [1] and scored $\geq 8$ points on the Panic Disorder Severity Scale-Self Report (PDSSSR) [23].

Thirty-five age- and gender-matched healthy controls (28 women; $M_{\text {age }}=42.5, S D=10.3$, range: $23-68$ years) completed the Mini-International Neuropsychiatric Interview [24, 25]; none met the diagnostic criteria for mental disorders and all had PDSS-SR scores of $\leq 8$ and Patient Health Questionnaire-9 (PHQ-9) scores of $\leq 10$.

\section{Measures}

The Mental Defeat Scale (MDS) is a 24-item questionnaire $[16,26]$ that measures mental defeat, using a 5-point Likert scale. Total scores range from 0 to 96, with higher scores indicating more severe mental defeat. The Cognitive Flexibility Scale (CFS) is a 12-item questionnaire $[27,28]$ that measures cognitive flexibility using a 6-point Likert scale. Total scores range from 12 to 72 , with higher scores indicating greater cognitive flexibility.

The PDSS-SR is a 7-item questionnaire that measures overall PD severity $[23,29,30]$ using a 5-point Likert scale. Total scores range from 0 to 28 , with higher scores indicating more severe PD symptoms. The Panic and Agoraphobia Scale is a 13-item questionnaire that measures PD symptom severity using a 5-point Likert scale $[31,32]$.

The PHQ-9 is a 9-item questionnaire that measures depression severity using a 4-point Likert scale [33, 34]. The Generalized Anxiety Disorder-7 scale is a 7-item questionnaire that measures the severity of generalized anxiety disorder using a 4-point Likert scale [35, 36]. The EuroQol-5D is a 5-item questionnaire that evaluates quality of life using a 3-point Likert scale [37, 38].

Patients with PD received 16 weekly, 50-min CBT sessions and completed all of the aforementioned questionnaires prior to CBT (baseline), mid-CBT (after 8 weeks), and post-CBT (after 16 weeks). The control group completed only the MDS, CFS, PDSS-SR, and PHQ-9 questionnaires prior to CBT (baseline).

\section{CBT intervention}

The CBT intervention focused on changes in the catastrophic misinterpretation of bodily sensations [39]. In addition, concepts relating to social anxiety disorder (SAD) in the Clark and Wells Model of Social Phobia were applied in the intervention [40], as PD has much in common with SAD [41-43]. After each session, patients completed homework, which enabled them to master new skills and use them in daily life. Eight clinical psychologists and two psychiatrists administered the CBT; the group was supervised on a weekly basis by a senior supervisor [44]. Further information regarding the CBT program is provided in Seki et al. [22].

The main treatment steps were as follows: (a) development of an individualized version of the cognitive-behavioral model of PD; (b) role-playing behavioral experiments with and without safety behaviors; (c) restructuring catastrophic self-imagery induced by bodily sensations; (d) practicing external focus and shifting attention; (e) behavioral experiments to assess negative catastrophic beliefs; (f) rescripting early memories associated with negative images in panic-related situations; (g) modification of problematic pre- and post-event processing; (h) discussing differences between participants' beliefs and those of others; (i) coping with persistent assumptions; and (j) relapse prevention. Pre-CBT, 
mid-CBT, and post-CBT assessments were implemented prior to session (a), at the beginning of session (e), and following session (j).

\section{Statistical analysis}

Demographic data from patients with PD and control participants were compared prior to CBT. Continuous variables were compared using a $t$ test, whereas categorical variables were compared using a Chi square test of association. Pre-CBT, mid-CBT, and post-CBT questionnaire scores were examined via a repeated-measures ANOVA. An ANOVA was performed to examine differences in the study variables between patients with PD and control participants. The post hoc analysis involved $t$ tests with a Bonferroni correction; effect sizes were calculated using Cohen's $d$ [45]. Associations between the study variables were examined over time and between groups using the Pearson's correlation coefficient. The significance level was set at $p<.05$. Data were analyzed using SPSS Version 23 (SPSS Inc., Chicago, IL, USA).

\section{Results \\ Demographic characteristics}

There were no significant differences in demographic characteristics between the patients with PD and the control participants, except in the category of "employment status." Patients with PD had a higher unemployment rate (Table 1 ).

Table 1 Participants' demographic characteristics

\begin{tabular}{|c|c|c|c|}
\hline Measure & Patients with PD $(n=15)$ & Control group $(n=35)$ & Statistics \\
\hline Age & 38.6 years (SD 9.6) & 42.5 years (SD 10.3) & $t(48)=-1.47, p=.15$ \\
\hline Gender & 13 female, 2 male & 28 female, 7 male & $x^{2}(1)=.00, p=1.00$ \\
\hline Educational background & & & $x^{2}(1)=6.17, p=.46$ \\
\hline High school & 2 & 4 & \\
\hline$<3$ years of college/university & 8 & 7 & \\
\hline$\geq 3$ years of college/university & 5 & 24 & \\
\hline Marital status & & & $x^{2}(1)=2.69, p=.26$ \\
\hline Single & 6 & 12 & \\
\hline Married & 8 & 23 & \\
\hline Divorced & 1 & 0 & \\
\hline Employment status & & & $x^{2}(1)=7.96, p=.02$ \\
\hline Employed full time & 5 & 19 & \\
\hline Part-time/homemaker & 7 & 16 & \\
\hline Unemployed & 3 & 0 & \\
\hline comorbid agoraphobia (M.I.N.I) & 13 & & \\
\hline \multicolumn{4}{|l|}{ Comorbid axis I diagnoses (M.I.N.I) } \\
\hline No comorbid condition (PD only) & 12 & & \\
\hline Depression & 1 & & \\
\hline Other anxiety disorder & 3 & & \\
\hline \multicolumn{4}{|l|}{ Medication } \\
\hline Benzodiazepine & 11 & & \\
\hline Antidepressant & 9 & & \\
\hline Benzodiazepine and antidepressant & 8 & & \\
\hline No medication & 3 & & \\
\hline \multicolumn{4}{|l|}{ Mental defeat } \\
\hline MDS mean (SD) & $22.2(16.6)$ & $5.4(5.3)$ & \\
\hline \multicolumn{4}{|l|}{ Cognitive flexibility } \\
\hline CFS mean (SD) & $42.8(9.7)$ & $52.6(7.5)$ & \\
\hline \multicolumn{4}{|l|}{ Associated psychopathology } \\
\hline PDSS-SR mean (SD) & $12.1(4.0)$ & $.1(.4)$ & \\
\hline PHQ-9 mean (SD) & $8.0(3.2)$ & $2.6(2.4)$ & \\
\hline
\end{tabular}

CFS Cognitive Flexibility Scale, MDS Mental Defeat Scale, M.I.N.I. Mini International Neuropsychiatric Interview, PD panic disorder, PDSS-SR Panic Disorder Severity Scale-Self Report, PHQ-9 Patient Health Questionnaire-9 


\section{Patients with PD: pre- versus mid-versus post-CBT assessment}

The average PDSS-SR and PHQ-9 scores of the patients with PD decreased significantly between the pre- and mid-CBT assessments, and between the pre- and postCBT assessments $(p<.05$; Table 2$)$.

The average pre-, mid-, and post-CBT MDS scores of the patients with PD were 22.2 (SD 16.6), 14.5 (SD 16.0), and 12.4 (SD 12.8), respectively (Table 2 ). The repeatedmeasures ANOVA indicated a significant change in MDS scores over time, $F(2,28)=7.54, p<.001$. Post-hoc $t$ tests indicated that the average MDS scores decreased significantly between the pre- and mid-CBT assessments $(d=.47)$ and between the pre- and post-CBT assessments $(d=.66)$.

The average pre-, mid-, and post-CBT CFS scores were 42.8 (SD 9.7), 49.4 (SD 7.8), and 49.5 (SD 5.9), respectively. The repeated-measures ANOVA indicated a significant change in CFS scores over time $F(2,28)=12.56$, $p<.001$. Post-hoc $t$ tests indicated that the average CFS scores increased between the pre- and mid-CBT assessments $(d=.75)$ and between the pre- and post-CBT assessments $(d=.83)$.

\section{Patients with PD versus control participants}

The ANOVA results showed that MDS scores differed significantly between the patients with PD and control participants, $F(3,76)=7.52, p<.01$. Post-hoc $t$ tests indicated that the pre-CBT MDS scores of the patients with PD were significantly higher than those of the control participants $(p<.05)$. Mid- and post-CBT scores did not differ significantly between the groups (Fig. 1).

Cognitive Flexibility Scale scores differed significantly between the patients with PD and the control participants, $F(3,76)=5.62, p<.01$. Post-hoc $t$ tests showed that the pre-CBT CFS scores of the patients with PD were significantly lower than those of the control participants $(p<.05)$. Mid- and post-CBT scores did not differ significantly between the groups (Fig. 1).

\section{Correlations}

Post-CBT MDS scores were significantly correlated with post-CBT CFS scores in both patients with PD $(r=-.709, p<.01)$ and control participants $(r=-.465$, $p<.01)$. No significant correlations were observed between the scores on GAD-7, PAS, or EuroQol-D5 in either group.

\section{Discussion}

Our findings showed that MDS scores of patients with PD decreased and their CFS scores increased between the pre- and post-CBT assessments. This finding suggests that CBT can reduce mental defeat and increase cognitive flexibility in the patients with PD.

Although no previous studies have examined pre- and post-CBT MDS scores, several sessions implemented in the present study, including those involving safety behaviors and attentional bias, have been an effective part of CBT treatment for SAD [4143]. These findings lend credibility to the use of CBT to treat mental defeat in patients with PD. By understanding the mechanisms underlying PD and the skills needed to manage symptoms, patients can reduce feelings of mental defeat, including helplessness and powerlessness.

Mid- and post-CBT scores did not differ significantly, perhaps because later sessions, including sessions (f) and (g), focused on the cognitive aspects of PD [41-43]; this may have stabilized reductions in mental defeat between the mid- and post-CBT assessments.

Table 2 Outcome measures for each assessment point

\begin{tabular}{|c|c|c|c|c|c|c|c|c|}
\hline \multirow[t]{2}{*}{ Measures } & \multirow{2}{*}{$\begin{array}{l}\text { Pre-CBT } \\
\text { Mean }(S D)\end{array}$} & \multirow{2}{*}{$\begin{array}{l}\text { Mid-CBT } \\
\text { Mean (SD) }\end{array}$} & \multirow{2}{*}{$\begin{array}{l}\text { Post-CBT } \\
\text { Mean (SD) }\end{array}$} & \multirow[t]{2}{*}{ Statistic } & \multicolumn{3}{|c|}{ Effect size (Cohen's $d$ ) } & \multirow[t]{2}{*}{ Post hoc } \\
\hline & & & & & $\begin{array}{l}\text { Pre- to mid- } \\
\text { CBT }\end{array}$ & $\begin{array}{l}\text { Mid- to post- } \\
\text { CBT }\end{array}$ & $\begin{array}{l}\text { Pre- to post- } \\
\text { CBT }\end{array}$ & \\
\hline \multicolumn{9}{|c|}{ Mental Defeat Scale } \\
\hline MDS & $22.2(16.6)$ & $14.5(16.0)$ & $12.4(12.8)$ & $F(2,28)=7.54, p<.01$ & .47 & .15 & .66 & $\begin{array}{l}\text { pre }>\text { mid } \\
\text { pre }>\text { post }\end{array}$ \\
\hline \multicolumn{9}{|c|}{ Cognitive flexibility } \\
\hline CFS & $42.8(9.7)$ & $49.4(7.8)$ & $49.5(5.9)$ & $F(2,28)=12.56, p<.01$ & .75 & .02 & .83 & $\begin{array}{l}\text { pre }<\text { mid } \\
\text { pre }<\text { post }\end{array}$ \\
\hline \multicolumn{9}{|c|}{ Associated psychopathology } \\
\hline PDSS-SR & $12.1(4.0)$ & $7.5(3.3)$ & $5.5(3.5)$ & $F(2,28)=19.04, p<.01$ & 1.26 & .59 & 1.77 & $\begin{array}{l}\text { pre }>\text { mid } \\
\text { pre }>\text { post }\end{array}$ \\
\hline PHQ-9 & $8.0(3.2)$ & $5.4(2.5)$ & $5.2(3.1)$ & $F(2,28)=6.48, p<.01$ & .91 & .07 & .89 & $\begin{array}{l}\text { pre }>\text { mid } \\
\text { pre }>\text { post }\end{array}$ \\
\hline
\end{tabular}




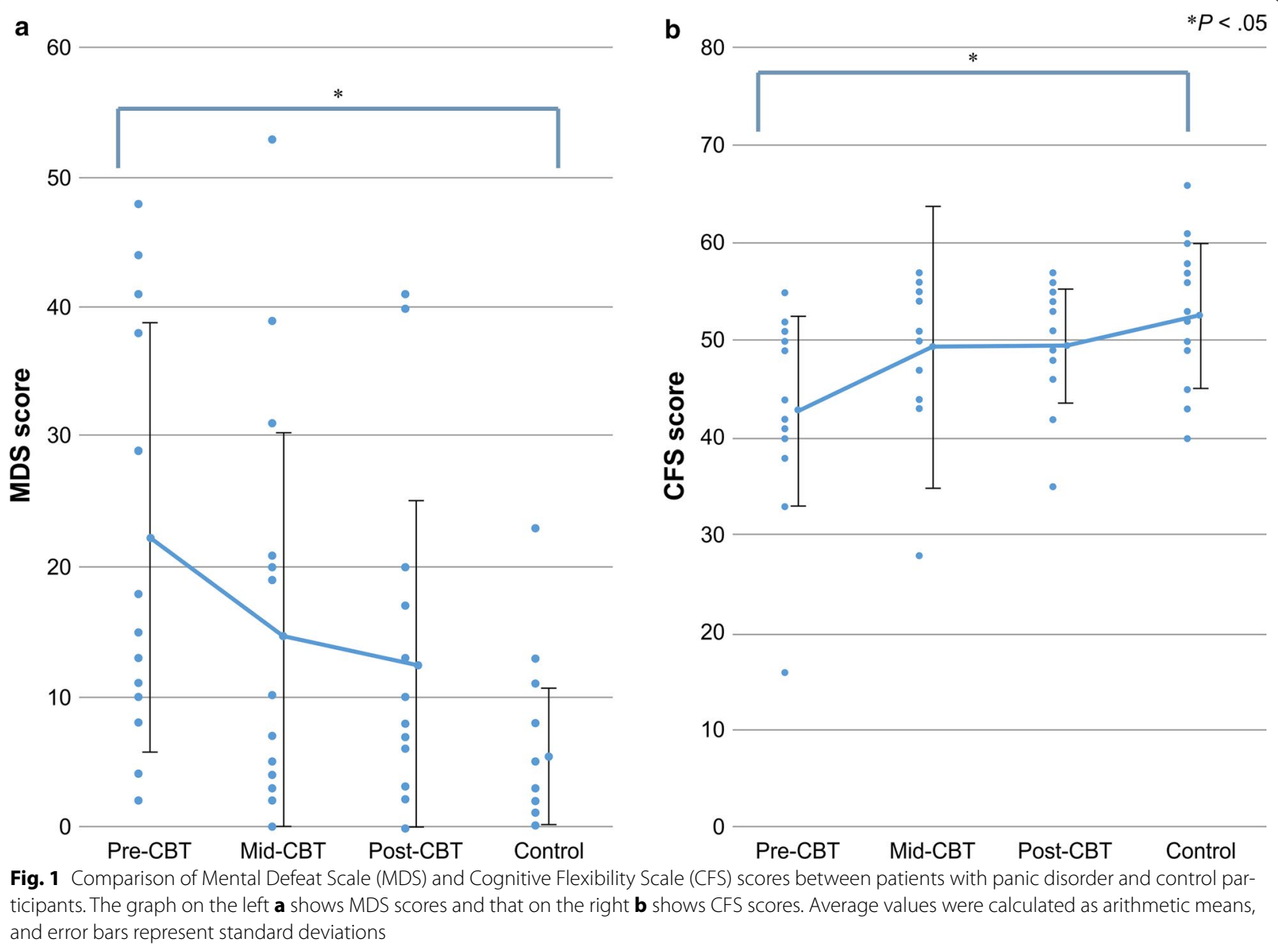

Cognitive behavioral therapy proved an effective treatment for enhancing cognitive flexibility, as it allowed patients to understand the mechanisms underlying PD and acquire skills to manage their symptoms. Consequently, patients were able to transform their initial catastrophic thoughts about panic symptoms (e.g., symptoms can kill) into objective thoughts (e.g., symptoms do not lead to death). This finding suggests that patients with $\mathrm{PD}$, whose cognitive distortions have become entrenched, can develop flexibility in their thinking.

As shown in Additional file 1, the nonclinical MDS scores observed in previous studies, including those of individuals with chronic pain, were much higher than those observed in the present study. This discrepancy may reflect the differences in the research approach and context, including variations in data-collection conditions and cultural factors. For example, subclinical symptoms of depression were not excluded in Oshiro and Shimizu's study [26]. Moreover, previous studies have reported a wide range of nonclinical CFS levels in various mental disorders $[19,20,27,28,46,47]$. This variation may also reflect the research and contextual differences.
Significant correlations were observed between postCBT MDS and CFS scores in both patients with PD and control participants, indicating that the MDS and CFS scores of patients with PD were similar to those of nonclinical populations following CBT.

\section{Conclusions}

The present study revealed that, although patients with PD initially exhibit more intense mental defeat and lower levels of cognitive flexibility than control participants do, the CBT intervention reduces mental defeat and increases cognitive flexibility to levels observed in nonclinical populations.

\section{Limitations}

The limitations of this study include the small sample size, gender disparity among participants, and the lack of follow-up assessment. The higher prevalence of PD in women than in men may explain the gender disparity [4]. The control group completed the questionnaires prior to CBT at baseline, therefore any impact of the passage of time on the measured outcomes was not 
evaluated. As the study did not include a randomized control group, it is unclear whether reductions in mental defeat and increases in cognitive flexibility resulted from CBT or from natural processes. Future research should involve randomized controlled trials with larger and more diverse samples, and should follow participants for a longer period. In addition, it is unclear which sessions led to the improvements observed. Future research should involve the administration of the MDS and CFS during all CBT sessions.

\section{Additional file}

Additional file 1. Comparison of scores on the Mental Defeat Scale and the Cognitive Flexibility Scale.

\section{Abbreviations}

CBT: cognitive behavioral therapy; CFS: Cognitive Flexibility Scale; MDS: Mental Defeat Scale; PD: panic disorder; PDSS-SR: Panic Disorder Severity Scale-Self Report; PHQ-9: Patient Health Questionnaire-9; PTSD: posttraumatic stress disorder; SAD: social anxiety disorder.

\section{Authors' contributions}

SN designed and managed the study, performed the statistical analyses, and drafted the manuscript. YS, TS, TM, YH, FY, MY, HI, NM, MK, and NK performed the clinical treatment and management. NY, YI, SA, KO, DM, YH, KY, MN, MI, and AN contributed to the study conception, supervised the CBT, and coordinated the trial. ES designed and supervised the overall implementation of the study. All authors critically revised the final manuscript. All authors read and approved the final manuscript.

\section{Author details}

1 Department of Cognitive Behavioral Physiology, Graduate School of Medicine, Chiba University, Chiba, 1-8-1 Inohana, Chuo-ku, Chiba-shi, Chiba 260-8670, Japan. ${ }^{2}$ Cognitive Behavioral Therapy Center, Chiba University Hospital, 1-8-1 Inohana, Chuo-ku, Chiba-shi, Chiba 260-8670, Japan. ${ }^{3}$ Organization for Promotion of Tenure Truck, University of Miyazaki, 1-1, Gakuenkibanadai-Nishi, Miyazaki 889-2192, Japan. ${ }^{4}$ Inada Clinic, Osaka, 2-6-5 Johoku-cho, Takatsuki, Osaka 569-0071, Japan. ${ }^{5}$ Clinic Adachi, Gifu, 62 Oikecho, Gifu, Gifu 500-8373, Japan. ${ }^{6}$ United Graduate School of Child Development, Osaka University, Kanazawa University, Hamamatsu University School of Medicine, Chiba University and University of Fukui, Suita, Chiba University, 1-8-1 Inohana, Chuo-ku, Chiba-shi, Chiba 260-8670, Japan. ${ }^{7}$ Department Psychiatry, Graduate School of Medicine, Chiba University, 1-8-1 Inohana, Chuo-ku, Chiba-shi, Chiba 260-8670, Japan. ${ }^{8}$ Research Centre for Child Mental Development, Chiba University, 1-8-1 Inohana, Chuo-ku, Chiba-shi, Chiba 260-8670, Japan.

\section{Acknowledgements}

Editorial support, which included medical writing, table assembly, creation of high-resolution images based on the authors' detailed directions, collation of authors' comments, copyediting, fact checking, and referencing, was provided by Editage.

\section{Competing interests}

NY has received speaking honoraria from the Japanese Psychiatric Nurses Association; writing honoraria from Igaku-Shoin, Nihon-Hyouronsha, and Sogensha; royalties for a book from Medical Friend Co. Ltd.; and grants from the Japanese Ministry of Health, Labor, and Welfare, and the Japan Society for the Promotion of Science. YI has received speaking honoraria from GlaxoSmithKline, Pfizer Japan, Sumitomo Dainippon Pharma, SHIONOGI \& Co., and Eli Lilly. KY has received speaking honoraria from MSD, Otsuka, Eli Lilly, and Dainihon Sumitomo. MI has received speaking honoraria from Janssen, Eli Lilly, Otsuka, Meiji Seika, Astellas, Dainippon Sumitomo, Ono, GlaxoSmithKline, Takeda, Mochida, Kyowa Hakko, MSD, Eisai, Daiichi-Sankyo, Novartis, Teijin,
Shionogi, Hisamitsu, and Asahi Kasei; a writing honorarium from Eli Lilly; royalties from Seiwa-Shoten and Zihousya; and consultant fees from Eli Lilly, Dainippon Sumitomo, Pfizer, and Abbott. Finally, SE has received speaking honoraria from medical education events supported by Eisai, Eli Lilly, GlaxoSmithKline, Janssen, Meiji Seika, Mochida, MSD, Otsuka, Pfizer, and Yoshitomi, and research grants from Pfizer Academic Contributions.

\section{Availability of data and materials}

Data generated from or analyzed in the current study are available from the corresponding author upon request.

\section{Consent for publication}

Not applicable.

\section{Ethics approval and consent to participate}

The study was approved by the ethics committee at the Chiba University Graduate School of Medicine (Reference Number: 1710). Written informed consent was obtained from all patients prior to assessment. The study was conducted in accordance with the Declaration of Helsinki and the Ethical Guidelines for Clinical Studies.

\section{Funding}

This work was supported by a JSPS KAKENHI Grant (JP15H06090).

\section{Publisher's Note}

Springer Nature remains neutral with regard to jurisdictional claims in published maps and institutional affiliations.

Received: 2 August 2017 Accepted: 6 January 2018

Published online: 12 January 2018

\section{References}

1. American Psychiatric Association. Diagnostic and statistical manual of mental disorders (DSM-5). 5th ed. Washington DC: American Psychiatric Association; 2013.

2. Ayusuo-Mateos JL. Global burden of panic disorder in the year 2000. Geneva: World Health Organization; 2000.

3. Naganuma Y, Tachimori H, Kawakami N, Takeshima T, Ono Y, Uda H, et al Twelve-month use of mental health services in four areas in Japan: find ings from the World Mental Health Japan Survey 2002-2003. Psychiatry Clin Neurosci. 2006;60:240-8.

4. Ministry of Health, Labor and Welfare. Panic Disorder/Anxiety Disorder. 2016. http://www.mhlw.go.jp/kokoro/speciality/detail_panic.html. Accessed 12 Nov 2016

5. Kohn R, Saxena S, Levav I, Saraceno B. The treatment gap in mental health care. Bull World Health Organ. 2004;82(11):858-66.

6. Otto MW, Tuby KS, Gould RA, McLean RY, Pollack MH. An effect-size analysis of the relative efficacy and tolerability of serotonin selective reuptake inhibitors for panic disorder. Am J Psychiatry. 2001;158(12):1989-92.

7. Hofmann SG, Smits JAJ. Cognitive behavioral therapy for adult anxiety disorders: a meta-analysis of randomized placebo-controlled trials. J Clin Psychiatry. 2008;69(4):621-32.

8. Klosko JS, Barlow DH, Tassinari R, Cery JA. A comparison of alprazolam and behavior therapy in treatment of panic disorder. J Psychother Pract Res. 1994:3(2):163-79

9. Clark DM, Salkovskis PM, Hackmann A, Middleton H, Anastasiades $\mathrm{P}$, Gelder M. A comparison of cognitive therapy, applied relaxation and imipramine in the treatment of panic disorder. Br J Psychiatry. 1994:164(6):759-69.

10. Roshanaei-Moghaddam B, Pauly MC, Atkins DC, Baldwin SA, Stein MB Roy-Byrne P. Relative effects of CBT and pharmacotherapy in depression versus anxiety: is medication somewhat better for depression, and CBT somewhat better for anxiety? Depress Anxiety. 2011;28(7):560-7.

11. Furukawa T. Psychotherapy plus antidepressant for panic disorder with or without agoraphobia: systematic review. Brit J Psychiatry. 2006:188(4):305-12. 
12. Furukawa TA, Watanabe N, Churchill R. Combined psychotherapy plus antidepressants for panic disorder with or without agoraphobia. Cochrane Database Syst Rev. 2007;1:CD004364.

13. Michelson LK, Marchione K. Behavioral, cognitive, and pharmacological treatments of panic disorder with agoraphobia: critique and synthesis. Consult Clin Psychol. 1991;59:100-14.

14. Ehlers A, Clark DM, Dunmore E, Jaycox L, Meadows E, Foa EB. Predicting response to exposure treatment in PTSD: the role of mental defeat and alienation. J Trauma Stress. 1998;11:457-71.

15. Ehlers A, Clark DM. A cognitive model of posttraumatic stress disorder. Behav Res Ther. 2000;38:319-45.

16. Tang NK, Salkovskis PM, Hanna M. Mental defeat in chronic pain: initial exploration of the concept. Clin J Pain. 2007;23(3):222-32.

17. Tang NK, Goodchild CE, Hester J, Salkovskis PM. Mental defeat is linked to interference, distress and disability in chronic pain. Pain 2010;149(3):547-54

18. Martin MM, Anderson CM. The Cognitive Flexibility Scale: three validity studies. Commun Rep. 1998;11(1):1-9.

19. Lounes N, Khan G, Tchanturia K. Assessment of cognitive flexibility in anorexia nervosa - self-report or experimental measure? A brief report. J Int Neuropsychol Soc. 2011;17(5):925-8.

20. Palm KM, Follette VM. The roles of cognitive flexibility and experiential avoidance in explaining psychological distress in survivors of interpersonal victimization. J Psychopathol Behav Assess. 2011;33(1):79-86.

21. Gunduz B. Emotional intelligence, cognitive flexibility and psychological symptoms in pre-service teachers. Glob J Psychol Behav Educ. 2013;11:102-20.

22. Seki Y, Nagata S, Shibuya T, Yoshinaga N, Yokoo M, Ibuki H, et al. A feasibility study of the clinical effectiveness and cost-effectiveness of individual cognitive behavioral therapy for panic disorder in a Japanese clinical setting: an uncontrolled pilot study. BMC Res Notes. 2016;9(1):458

23. Shear MK, Rucci P, Williams J, Fra E, Grochocinski V, Vander B, et al. Reliability and validity of the Panic Disorder Severity Scale: replication and extension. J Psychiatr Res. 2001;35:293-6.

24. Sheehan DV, Lecrubier $Y$, Sheehan KH, Amorim $P$, Janavs J, Weiller E, et al. The Mini-International Neuropsychiatric Interview (M.I.N.I.): the develop ment and validation of a structured diagnostic psychiatric interview for DSM-IV and ICD-10. J Clin Psychiatry. 1998;59:22-33.

25. Sheehan DV, Lecrubier Y, Otsubo T. Brief structured interview for psychiatric disorders: M.I.N.I. and M.I.N.I. KID. Rinsho-Seishin-Igaku. 2010;39:43-8.

26. Oshiro K, Shimizu E. Development and validation of the Japanese version of Mental Defeat scale (unpublished observations submitted).

27. Martin M, Rubin R. A new measure of cognitive flexibility. Psychol Rep. 1995;76:623-6.

28. Oshiro K, Nagaoka S, Shimizu E. Development and validation of the Japanese version of cognitive flexibility scale. BMC Res Notes. 2016:9(1):275.

29. Houck PR, Spiegel DA, Shear MK, Rucci P. Reliability of the self-report version of the Panic Disorder Severity Scale. Depress Anxiety. 2002;15:183-5.

30. Katagami M. The self-report version of the Panic Disorder Severity Scale: reliability and validity of the Japanese version. Jpn J Psychosom Med. 2007:47:331-8

31. Bandelow B. Assessing the efficacy of treatments for panic disorder and agoraphobia. II. The Panic and Agoraphobia Scale. Int Clin Psychopharmacol. 1995;10:73-81.

32. Kaiya $H$, Yoshida $E$, Kumano $H$. Reliability and validity of the Japanese version of the Panic and Agoraphobia Scale (PAS-J). Rinsho-Seishin-Igaku (Jpn J Clin Psychiatry). 2008:37:1053-64.
33. Spitzer RL, Kroenke K, Williams JB. Validation and utility of a self-report version of PRIME-MD: the PHQ primary care study. Primary care evaluation of mental disorders. Patient Health Questionnaire. JAMA 1999;282(18):1737-44.

34. Muramatsu K, Miyaoka H, Kamijima K, Muramatsu Y, Yoshida M, Otsubo T, et al. The Patient Health Questionnaire, Japanese version: validity according to the Mini-International Neuropsychiatric Interview-Plus. Psychol Rep. 2007;101:952-60.

35. Spitzer RL, Kroenke K, Williams JB, Löwe B. A brief measure for assessing generalized anxiety disorder: the GAD-7. Arch Intern Med. 2006:22:1092-7.

36. Muramatsu K. An up-to-date letter in the Japanese version of PHQ, PHQ9, PHQ-15. Niigata Seiryo Daigakudaigakuin Rinshosinrigakukenkyu (Grad School Niigata Seiryo Uni Clin Psychol Res). 2014;7:35-9.

37. EuroQol Group. A new facility for the measurement of health-related quality of life. Health Policy. 1990;16:199-208.

38. Tsuchiya A, Ikeda S, Ikegami N, Nishimura S, Sakai I, Fukuda T, et al. Estimating an EQ-5D population value set: the case of Japan. Health Econ. 2002;11:341-53.

39. Clark DM, Salkovskis PM, Öst LG, Breitholtz E, Koehler KA, Westling BE, et al. Misinterpretation of body sensations in panic disorder. J Consult Clin Psychol. 1997:65:203-13.

40. Clark D, Wells A. A cognitive model of social phobia. In: Heimberg RG, Liebowitz MR, Hope DA, Schneier FR, editors. Social phobia: diagnosis, assessment, and treatment. New York: Guilford Press; 1995. p. 69-93.

41. Yoshinaga N, Niitsu T, Hanaoka H, Sato Y, Oshima F, Matsuki S, et al. Strategy for treating selective serotonin reuptake inhibitor-resistant social anxiety disorder in the clinical setting: a randomised controlled trial protocol of cognitive behavioral therapy in combination with conventional treatment. BMJ Open. 2013;3(2):e00224.

42. Yoshinaga N. A preliminary study of individual cognitive behavior therapy for social anxiety disorder in Japanese clinical settings: a single-arm, uncontrolled trial. BMC Res Notes. 2013:6:74.

43. Yoshinaga N, Matsuki S, Niitsu T, Sato Y, Tanaka M, Ibuki H, et al. Cognitive behavioral therapy for patients with social anxiety disorder who remain symptomatic following antidepressant treatment: a randomized, assessor-blinded, controlled trial. Psychother Psychosom. 2016;85(4):208-17.

44. Blackburn IM, James IA, Milne DL, Baker C, Standart S, Garland A, et al. The revised Cognitive Therapy Scale (CTS-R): psychometric properties. Behav Cogn Psychother. 2001:29:431-46.

45. Cohen J. Statistical power analysis forthe behavioral sciences. 2nd ed. Hillsdale: Erlbaum; 1988

46. Lee JK, Orsillo SM. Investigating cognitive flexibility as a potential mechanism of mindfulness in generalized anxiety disorder. J Behav Ther Exp Psychiatry. 2014;45(1):208-16.

47. Johnco C, Wuthrich VM, Rapee RM. The influence of cognitive flexibility on treatment outcome and cognitive restructuring skill acquisition during cognitive behavioural treatment for anxiety and depression in older adults: results of a pilot study. Behav Res Ther. 2014;57:55-64.

\section{Submit your next manuscript to BioMed Central and we will help you at every step:}

- We accept pre-submission inquiries

- Our selector tool helps you to find the most relevant journal

- We provide round the clock customer support

- Convenient online submission

- Thorough peer review

- Inclusion in PubMed and all major indexing services

- Maximum visibility for your research

Submit your manuscript at www.biomedcentral com/submit
C BioMed Central 